\title{
Vanadium Effect on a Medium Carbon Forging Steel
}

\author{
Carlos Garcia-Mateo ${ }^{1, *}$, Lucia Morales-Rivas ${ }^{1,2}$, Francisca G. Caballero ${ }^{1}$, David Milbourn ${ }^{3}$ \\ and Thomas Sourmail $4, *$ \\ 1 National Centre for Metallurgical Research, Physical Metallurgy Department, MATERALIA Research \\ Group (CENIM-CSIC), Avda Gregorio del Amo, 8, Madrid E-28040, Spain; rivas@mv.uni-kl.de (L.M.-R.); \\ fgc@cenim.csic.es (F.G.C.) \\ 2 University of Kaiserslautern, Materials Testing Group, Gottlieb-Daimler-Str., Kaiserslautern 67663, Germany \\ 3 Vanitec Ltd., Suite 5, 90 Calvery Road, Tumbridge Wells, Kent TN1 2UN, UK; david.milbourn@vanitec.org \\ 4 Asco Industries-CREAS (Research Centre), Metallurgy, BP 70045, 57301 Hagondange Cedex, France \\ * Correspondence: cgm@cenim.csic.es (C.G.-M.); thomas.sourmail@ascometal.com (T.S.); \\ Tel.: +34-91-553-89-00 (C.G.-M.); +33-(0)3-87-70-73-16 (T.S.)
}

Academic Editor: Isabel Gutierrez

Received: 29 March 2016; Accepted: 26 May 2016; Published: 30 May 2016

\begin{abstract}
In the present work the influence of vanadium on the hardenability and the bainitic transformation of a medium carbon steel is analyzed. While $\mathrm{V}$ in solid solution enhances the former, it hardly affects bainitic transformation. The results also reveal an unexpected result, an increase of the prior austenite grain size as the $\mathrm{V}$ content increases.
\end{abstract}

Keywords: vanadium; forging; medium carbon; bainite; hardenability

\section{Introduction}

Traditionally, forging steels used for automotive applications have been of two types, precipitation hardening ferritic-pearlitic steels and the quenched and tempered forging steels. To be on par with the mechanical properties of the quenched and tempered steels, the precipitation hardening grades include controlled additions of $\mathrm{Ti}, \mathrm{Nb}$ and $\mathrm{V}$. Those have a major role in the control of the austenite grain size and precipitation hardening, for example by fine dispersion of $\mathrm{V}$ precipitates on as-forged parts after natural cooling [1]. Some advantages of the precipitation hardening steels as compared to the quenched and tempered ones are the elimination of extra heat treatments due to a controlled cooling right after the forging procedures, and better machinability. Still, ferritic-pearlitic microstructures in forging steels tend to exhibit inferior values of yield strength and toughness as compared to tempered martensite. An alternative microstructure, bainite, has been revealed as a way to improve toughness while maintaining or even increasing strength levels [2,3]. The increase in strength for the ferritic-pearlitic steels is achieved by the reduction of the ferrite fraction, the decrease in the pearlite lamella spacing and the addition of the microalloying elements such as V, which results in additional precipitates. The aimed microstructure in the bainitic steel consists mainly of bainitic ferrite and retained austenite instead of carbides [4] as the bainitic second phase [5]. Not only because of the improvement on the mechanical response of the microstructure but also because of the simplicity of the heat treatment to attain bainite, there has been an increasing interest in the use of this microstructure for forged products [6-10]. Such bainitic steels are designed to provide suitable bainitic microstructure after hot forging or rolling by natural cooling. As the precipitation of $\mathrm{V}$ carbides does not occur during the bainitic transformation, the use of $\mathrm{V}$ is not as extended in these grades as in the more conventional ferritic-pearlitic steels. However, $\mathrm{V}$ is of interest for its role in increasing hardenability [11-14]; therefore, it allows us to obtain homogeneous microstructures in thicker sections. A possible mechanism for the effect of $\mathrm{V}$ on hardenability was given in References $[15,16]$, where it is proposed that V segregates to the grain boundaries, thereby increasing the hardenability. Regarding the effect that $\mathrm{V}$ has on the bainitic 
transformation, it is not uncommon to find works where V-bearing steels are used in the context of bainitic steels, but invariably, in all cases, there is an important percentage of the microalloying element precipitated for various purposes [17-22]; therefore, the role that $\mathrm{V}$ in solid solution plays on bainitic transformation needs further description.

The present study is concerned with quantifying both effects, hardenability and bainite transformation kinetics, by using a medium carbon steel with and without $\mathrm{V}$.

\section{Materials and Methods}

The two materials concerned in this study were manufactured using a vacuum induction melting furnace to produce $20 \mathrm{~kg}$ ingots. After solidification and cooling to room temperature, the ingots were re-heated to about $1250{ }^{\circ} \mathrm{C}$ and hot-forged to bars of $40 \mathrm{~mm}$ diameter. The corresponding chemical compositions are detailed in Table 1.

Table 1. Chemical composition of the alloys investigated in the present study, all in wt. \% except where indicated.

\begin{tabular}{cccccccccc}
\hline Alloy & $\mathbf{C}$ & $\mathbf{S i}$ & $\mathbf{M n}$ & $\mathbf{C r}$ & $\mathbf{M o}$ & $\mathbf{V}$ & $\mathbf{T i}$ & $\mathbf{B}$ & $\mathbf{N}$ \\
\hline $\mathbf{0} \mathbf{~ V}$ & 0.24 & 0.70 & 1.53 & 0.78 & 0.08 & 0.01 & 0.025 & $30 \mathrm{ppm}$ & $80 \mathrm{ppm}$ \\
$\mathbf{2 0 0} \mathbf{~ V}$ & 0.24 & 0.70 & 1.58 & 0.79 & 0.08 & 0.21 & 0.025 & $30 \mathrm{ppm}$ & $80 \mathrm{ppm}$ \\
\hline
\end{tabular}

A Bahr 805D high-resolution dilatometer (TA Instruments, New Castle, DE, USA) was used to build continuous cooling transformation diagrams (CCT) and to track the isothermal decomposition of austenite into bainite at different temperatures. Samples of $4 \mathrm{~mm}$ diameter and $10 \mathrm{~mm}$ in length were extracted from the mid-radius of the bars. For reasons that will be later clarified, in all cases, austenitization was established at $1150{ }^{\circ} \mathrm{C}$ for $3 \mathrm{~min}$ to allow complete homogenization of the temperature, followed by different cooling rates down to room temperature using Ar. In the case of the isothermal treatments, austenitization samples were cooled down at $20^{\circ} \mathrm{C} / \mathrm{s}$ to the selected bainitic transformation temperatures $\left(375,400\right.$ and $\left.425^{\circ} \mathrm{C}\right)$ where the specimens were held until the end of the transformation.

Metallographic samples were cut, ground, and polished following the standard procedures. A $4 \%$ Nital etching solution (4 vol. \% of nitric acid + 96 vol. \% of ethanol) was used to reveal the different microstructures. In order to determine the prior austenite grain size (PAGS), the thermal etching technique was used [23]. It only requires the preparation of a finely polished surface of the specimen ( $1 \mu \mathrm{m}$ diamond cloth) and the application of high vacuum conditions during the heat treatment to avoid oxide formation that would darken the polished surface. At high temperatures, preferential diffusion takes places at the intersection of the austenite grain boundaries and the free polished surface, forming grooves. After heating, slow cooling is generally preferred rather than fast cooling because the latter promotes the formation of surface reliefs due to martensitic and/or bainitic transformations that can mask the PAGS.

Scanning electron microscopy (SEM) observations were carried out on a JEOL J8M-6500 field emission gun (SEM-FEG, JEOL Ltd., Tokyo, Japan) operating at $10 \mathrm{kV}$.

$\mathrm{X}$-ray diffraction analysis was used to determine the fraction of retained austenite $(\mathrm{V} \gamma)$ on selected conditions. For this purpose, specimens of the different bainitic microstructures were prepared by standard procedures. To remove the deformed layer where austenite might have transformed to martensite by the TRIP (Transformation induced plasticity) effect during sample preparation, several cycles of etching and polishing were applied. XRD measurements were carried out in a Bruker AXS D8 diffractometer (Bruker AXS Inc., Fitchburg, WI, USA) equipped with a Co X-ray tube. A current of $30 \mathrm{~mA}$ and a voltage of $40 \mathrm{kV}$ were employed as tube settings. The XRD data were collected over $2 \mathrm{~h}$ in the range of $35^{\circ}-135^{\circ}$ with a step size of $0.01^{\circ}$. The volume fraction of the retained austenite was calculated from the integrated intensities of (111), (002), (022), and (113) austenite peaks, and those of 
(011), (002), and (112) planes of ferrite, with the equation for the ratio of these experimental values to the normalization factors for peak intensity $(R)$ given in the ASTM E975-13 [24]. The use of several Bragg peaks in evaluating the amount of retained austenite diminished the detrimental influence of the texture, as long as it remains small to moderate [25].

In selected conditions the fraction of $\mathrm{V}$ precipitates was determined using a combination of electrolytic dissolution and inductively coupled plasma (ICP) spectrometry. The chemical extraction of precipitates is carried out by electrolytic dissolution of a steel sample with an electrolyte composed of lithium chloride and salicylic acid diluted in methanol. With this method, only the steel matrix is dissolved. The precipitates are recovered by filtration. The filtrate is then dissolved in an acid solution composed of hypochloric, nitric and hydrofluoric acids. The obtained solution is analyzed by ICP spectrometry in order to obtain the amount of $\mathrm{Nb}, \mathrm{Ti}, \mathrm{Al}, \mathrm{V}$ and Fe contained in precipitates, compared to the total amount of these elements in the steels.

Hardness Vickers (HV) measurements represent a mean of at least three measurements with a typical variation of only $\pm 4 \mathrm{HV}$.

All the necessary thermodynamics calculations were performed using MtData in combination with the SGSOL-SGTE Solution database [26].

\section{Results and Discussion}

As anticipated, these materials, Table 1, are intended to achieve bainitic microstructures without the need of a specific heat treatment, i.e., by natural cooling either after hot rolling or forging. To obtain a microstructure representative of the industrial process, already hot-forged bars of $40 \mathrm{~mm}$ are normalized at $1000{ }^{\circ} \mathrm{C}$ for $45 \mathrm{~min}$ and then air-cooled. This heat treatment leads to a microstructure representative of forged conditions in terms of grain size and mechanical properties. The microstructure thus obtained, as shown in Figure 1, reveals that the bars exhibit a homogeneous bainitic structure after normalization, consisting of a mixture of carbide-free bainite and retained austenite. A refinement of the microstructure in the V-bearing alloy is observed and confirmed by SEM, as shown in Figure 1, even though both microstructures have very similar HV values and the same amount of retained austenite, as shown in Table 2. Blocky features of retained austenite are indicated by arrows in Figure 1, and more austenite is also placed between the bainitic ferrite plates as films. Differences in the scale of the microstructure could be partially explained in terms of the temperature range where bainitic transformation takes place, Bs and Ms in Table 3. As it is lower for the $200 \mathrm{~V}$ steel than for the $0 \mathrm{~V}$ steel, the refinement of the bainitic ferrite plates is enhanced [2,27]. This is in agreement with the experimental Bs temperature obtained for a cooling rate of $2{ }^{\circ} \mathrm{C} / \mathrm{s}$ using data obtained from the CCT diagrams, as seen in Table 3, showing that indeed there is a clear trend for a decrease in the Bs temperature with the increased vanadium content.

From the $200 \mathrm{~V}$ equilibrium calculations it can be safely concluded that at both austenitization temperatures used, 1000 and $1150{ }^{\circ} \mathrm{C}$, most of the $\mathrm{V}$ is in solid solution, as shown in Figure 2. In such calculations, the existence of ferrite, austenite, cementite, $\mathrm{AlN}, \mathrm{MnS}, \mathrm{TiN} \mathrm{V}(\mathrm{C}, \mathrm{N})$ and all the elements listed above in the chemical composition of the alloy were allowed. It is not expected that in the case of the normalized condition $\left(1000^{\circ} \mathrm{C}, 45 \mathrm{~min}\right)$ any substantial amount of $\mathrm{V}$ precipitates. To further support this point, the electrolytic dissolution technique was used to determine the fraction of $\mathrm{V}$ precipitates in both steels, as shown in Table 3. It can be concluded that in this state, representative of the forging state, most of the vanadium seems to be in solid solution. 

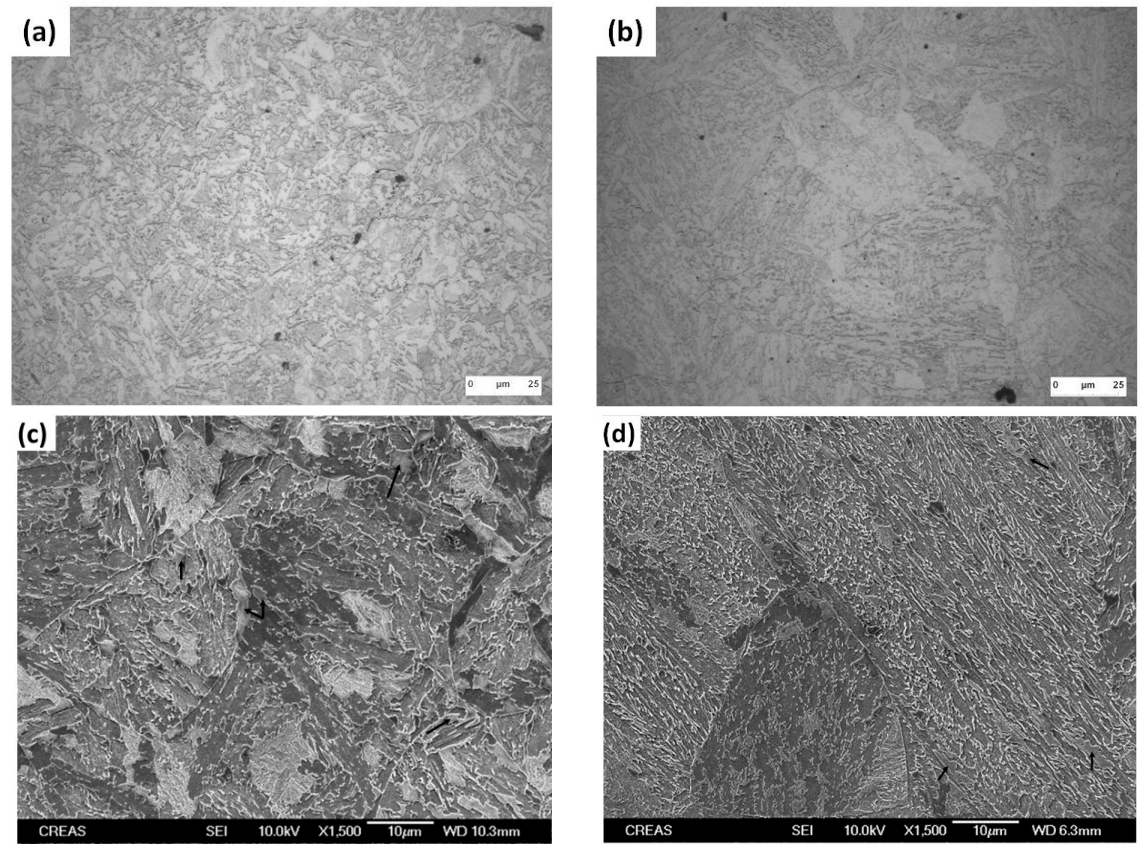

Figure 1. Examples of the microstructure after natural cooling from $1000{ }^{\circ} \mathrm{C},(\mathbf{a}, \mathbf{c})$ for $0 \mathrm{~V}$ alloy and (b,d) for $200 \mathrm{~V}$ alloy. Arrows indicate the presence of small blocks of austenite, and more austenite is also placed between the bainitic ferrite plates as films.

Table 2. Hardness (HV30) and retained austenite fraction $(\mathrm{V} \gamma)$ after simulated forged conditions. Prior austenite grain size (PAGS) measured at $1150{ }^{\circ} \mathrm{C}$.

\begin{tabular}{cccc}
\hline Alloy & HV30 & V $\gamma(\mathbf{\%})$ & PAGS $(\boldsymbol{\mu m})$ \\
\hline $0 \mathrm{~V}$ & 346 & $15 \pm 3$ & $12 \pm 2$ \\
$200 \mathrm{~V}$ & 344 & $15 \pm 3$ & $22 \pm 3$ \\
\hline
\end{tabular}
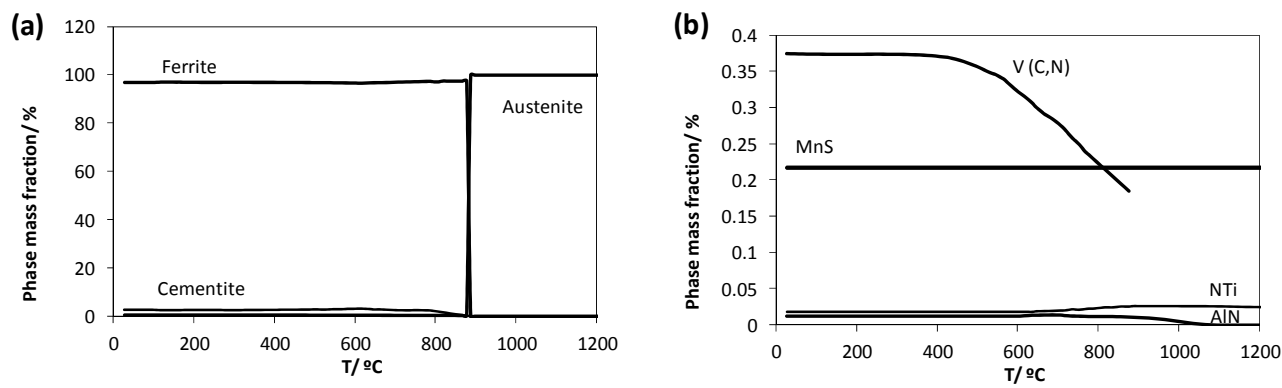

Figure 2. MtData calculations for the determination of equilibrium phases in $200 \mathrm{~V}$ alloy, (a) results for ferrite, austenite and cementite and (b) for $\mathrm{AlN}, \mathrm{MnS}$, TiN V(C,N).

Table 3. Calculated Bs and Ms temperatures as in [2]. Experimental Bs temperature derived from the $2{ }^{\circ} \mathrm{C} / \mathrm{s}$ curves of the corresponding CCT diagrams in Figure 3, and experimental V precipitate content in the grades after normalization at $1000^{\circ} \mathrm{C}$.

\begin{tabular}{cccccc}
\hline \multirow{2}{*}{ Alloy } & \multicolumn{2}{c}{ Theoretical } & Experimental & \multicolumn{2}{c}{ V Precipitate } \\
\cline { 2 - 6 } & Bs $\left({ }^{\circ} \mathbf{C}\right)$ & Ms $\left({ }^{\circ} \mathbf{C}\right)$ & Bs $\left({ }^{\circ} \mathbf{C}\right)$ & ppm & $\%$ \\
\hline $0 \mathrm{~V}$ & 522 & 369 & 533 & 0 & 0 \\
$200 \mathrm{~V}$ & 514 & 361 & 515 & 7 & 1 \\
\hline
\end{tabular}


For further understanding the effect that $\mathrm{V}$ might have on hardenability, construction of the CCT diagrams was performed using, as austenitization conditions, $1150^{\circ} \mathrm{C}$ for $3 \mathrm{~min}$, to obtain a grain size representative of the forged components. The CCT diagrams thus obtained are presented in Figure 3. At low cooling rates, both alloys transform to a mixture of ferrite-pearlite with variable amounts of bainite and martensite (see the $0.15{ }^{\circ} \mathrm{C} / \mathrm{s}$ microstructures in Figures 4 and 5). As the cooling rate increases, the amount of ferrite and pearlite decreases and gives way to displacive transformation products such as bainite and martensite (see 0.5 and $10{ }^{\circ} \mathrm{C} / \mathrm{s}$ microstructures in Figures 4 and 5). Finally, when the cooling rate is high enough martensite is the only transformation product (see Figure 3 and the microstructure in Figures 4 and 5 corresponding to the $50{ }^{\circ} \mathrm{C} / \mathrm{s}$ cooling rate). In a similar manner, from these same CCT diagrams, as shown in Figure 3, the critical cooling rate, understood as that where no more ferrite-pearlite is found, can be estimated as 1 and $0.5^{\circ} \mathrm{C} / \mathrm{s}$ for $0 \mathrm{~V}$ and $200 \mathrm{~V}$ steel, respectively, see Figure 3. As anticipated, the Bs temperature can be obtained for a cooling rate of $2{ }^{\circ} \mathrm{C} / \mathrm{s}$ using data obtained from these same diagrams, as shown in Table 3. Therefore, it is clear that $\mathrm{V}$ in solid solution decreases the measured Bs temperature and also, from the data presented in Figures $3-5$ that it enhances the hardenability.
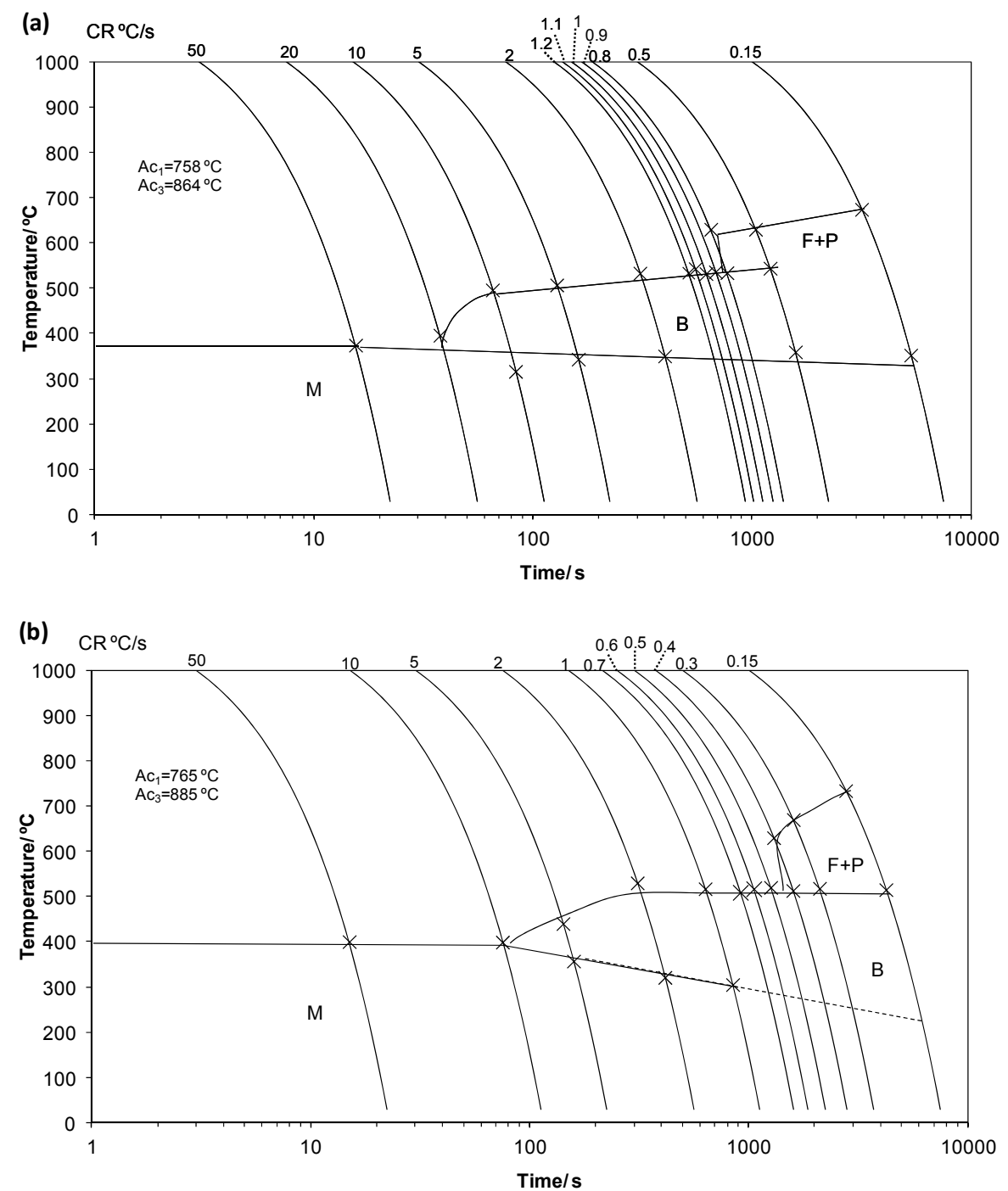

Figure 3. CCT diagrams for the (a) $0 \mathrm{~V}$ and (b) $200 \mathrm{~V}$ alloys, where $\mathrm{F}$ stands for ferrite, $\mathrm{P}$ for pearlite, $\mathrm{B}$ for bainite and $\mathrm{M}$ for martensite. 

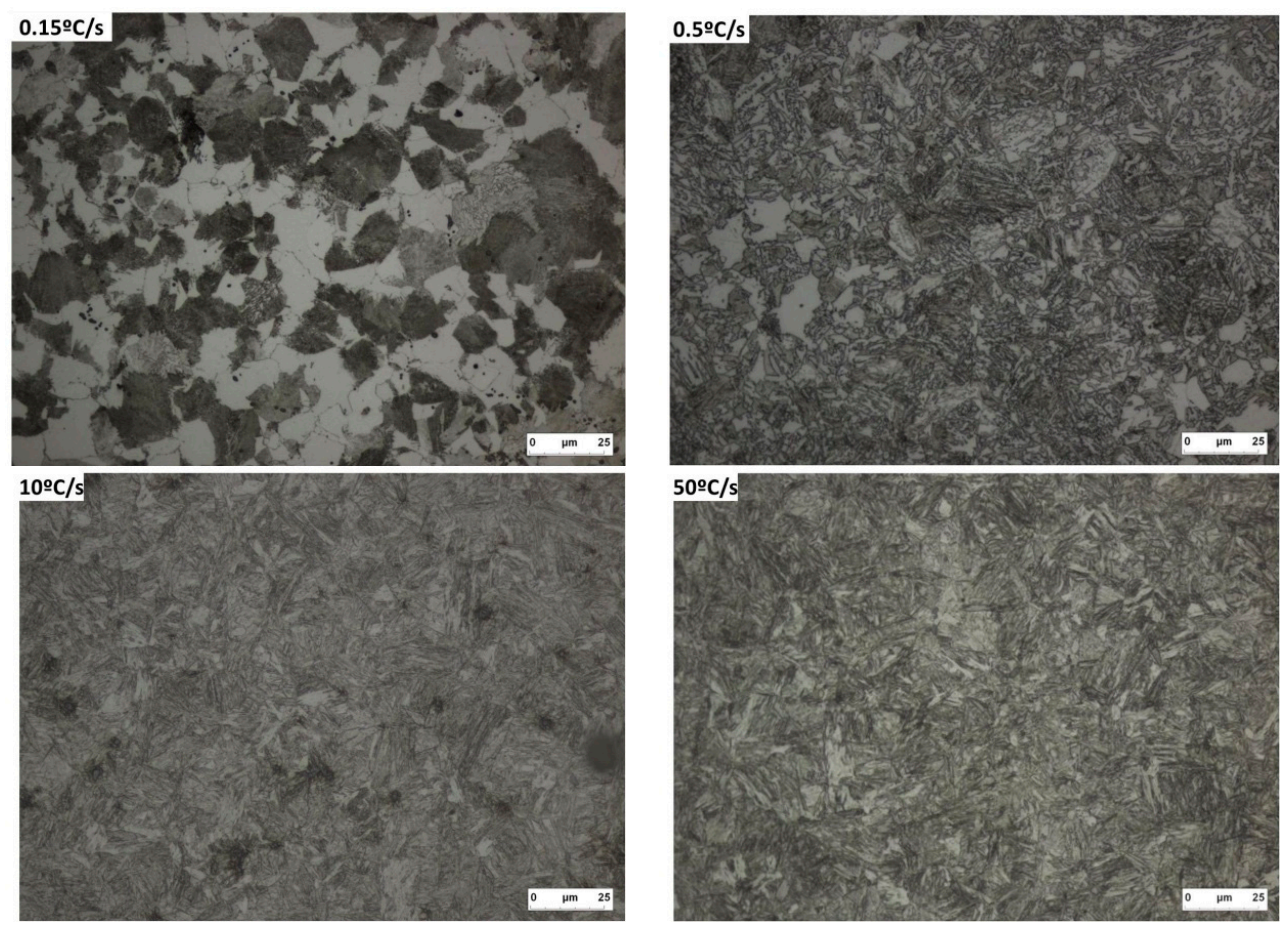

Figure 4. Examples of the microstructure obtained for $0 \mathrm{~V}$ alloy at different cooling rates, as indicated in the corresponding micrographs, i.e., $0.15,0.5,10$ and $50{ }^{\circ} \mathrm{C} / \mathrm{s}$. Phase identification should be done according to Figure 3.
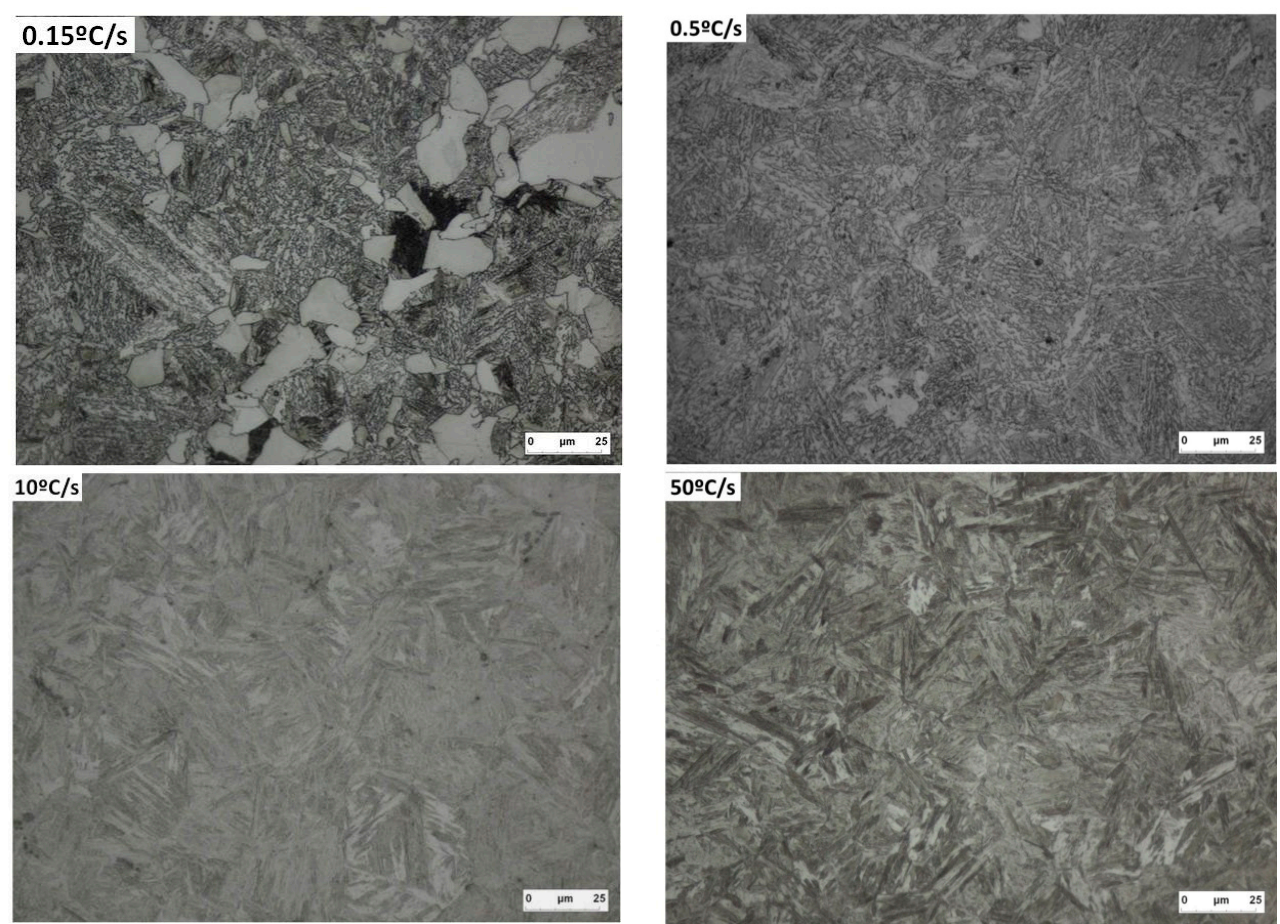

Figure 5. Examples of the microstructure obtained for $200 \mathrm{~V}$ alloy at different cooling rates, as indicated in the corresponding micrographs, i.e., $0.15,0.5,10$ and $50^{\circ} \mathrm{C} / \mathrm{s}$. Phase identification should be done according to Figure 3. 
When the PAGS is measured after $1150{ }^{\circ} \mathrm{C}$ during $3 \mathrm{~min}$, as shown in Table 2, an increase is observed in the austenite grain size for the $\mathrm{V}$ alloyed grade, 12 vs. $22 \mu \mathrm{m}$. Examples of the grooves obtained by thermal etching are shown in Figure 6.
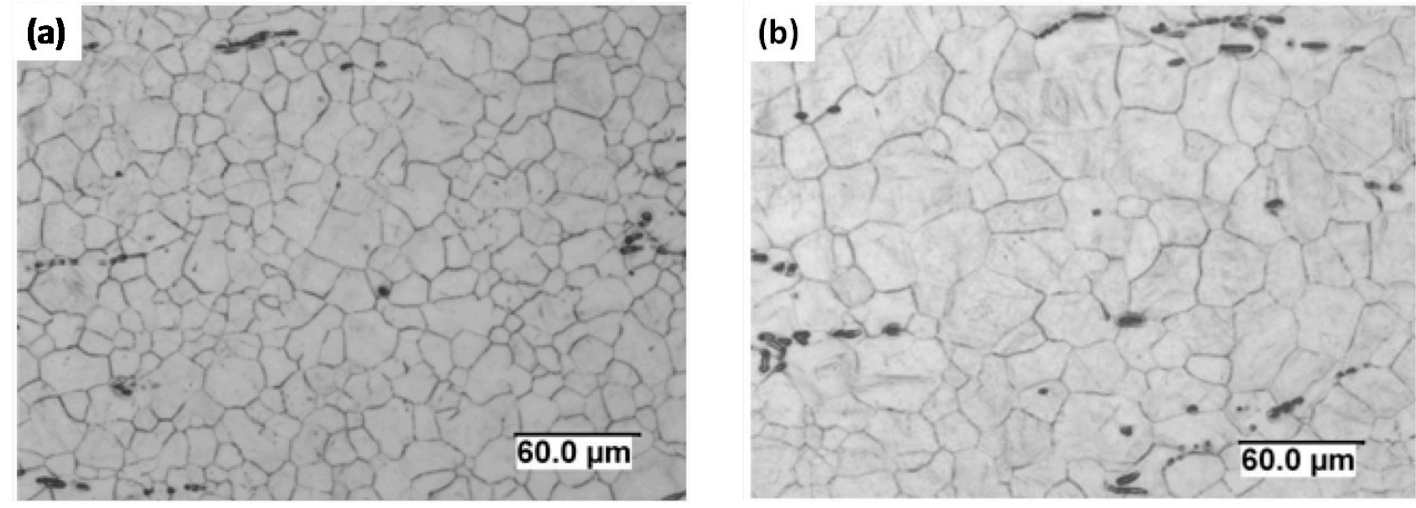

Figure 6. Prior austenite grain boundaries revealed by thermal etching after heating to $1150{ }^{\circ} \mathrm{C}$ for $3 \mathrm{~min}$, (a) for $0 \mathrm{~V}$ and (b) $200 \mathrm{~V}$ alloy.

The reported change in the austenite average grain size, as shown in Table 2, with the V-bearing steel having a bigger PAGS than the $0 \mathrm{~V}$ steel, is unexpected. In the absence of V precipitates that could pin austenite grain boundaries, and given that both alloys contain the same level of $\mathrm{N}$, a similar grain size would be expected in both steels [28]. In addition, the presence of V in solid solution should not result in a reduction of the grain size, due to the limited drag effect of $\mathrm{V}$ as compared with other elements $[29,30]$. An indirect influence on $\operatorname{Ti}(C, N)$ precipitation appears as a likely cause for the present observation [31], though this issue is considered outside the scope of the paper and is not further discussed.

It can be argued that the increase in PAGS is the sole reason explaining the detected increase in hardenability. Attempts to attain the same PAGS on both alloys were dismissed as it would imply an increase of the temperature close to the technical limit of the equipment for the $0 \mathrm{~V}$ steel, or a decrease of the temperature to such range that V would no longer be in the solution in the case of the $200 \mathrm{~V}$ steel. Therefore, it is not straightforward to isolate the effect that $\mathrm{V}$ in solid solution has on the hardenability. It has been reported that $\mathrm{V}$ in solid solution enhances hardenability greatly and is more effective than any of the conventional hardenability additives, even at small quantities [11-14]. Using the hardenable diameter concept introduced in Reference [12], it is possible to estimate that a change of the grain size of the order shown in Table 2 leads to a variation of the diameter of $3 \mathrm{~cm}$, while a variation of $0.2 \mathrm{wt}$. \% of $\mathrm{V}$ leads to an increase of almost $6.5 \mathrm{~cm}$. Thus, it is not reasonable to explain, solely based in the reported differences in PAGS, the change in the critical cooling rate to avoid ferrite-pearlite, as shown in Figure 3. Therefore, the $\mathrm{V}$ influence on the hardenability must play an important role.

Finally, the kinetics of bainitic transformation at different isothermal temperatures, namely 375,400 and $425^{\circ} \mathrm{C}$, was investigated by means of dilatometry, as shown in Figure 7 . Given the asymptotic nature of the curves in Figure 7, the reported time to complete the transformation in Table 4 corresponds to that required to reach $90 \%$ of the maximum strain. In contrast with the CCT observation, where $\mathrm{V}$ seemed to have an important role on the kinetics of different transformation products, the isothermal transformation of bainite is somewhat unaffected. Dilatometric signals in Figure 7 are almost identical not only in terms of magnitude and the amount of bainite formed, but also in the shape of the curves, how the transformation proceeds and the beginning and end of the transformation, i.e., transformation kinetics. To some extent this result is expected, as is predicted by the bainitic transformation theory [2,32]. The $T_{0}$ line in Figure 8 accounts for how far the bainitic transformation can proceed before it becomes thermodynamically impossible for the austenite to transform to bainite, i.e., it can help in getting an idea of the amount of bainitic ferrite formed at a given temperature, with 
the horizontal line $d$ in Figure 8 being proportional to the fraction of bainite, identical for both steels. Note that, given the negative slope of the $T_{0}$ line, the lower the transformation temperature is, the higher the fraction of bainitic ferrite that can form is, which experimentally reflects in an increase of the magnitude of the dilatometric signal with the decreasing transformation temperature in Figure 7. Also, the calculated free energy change for the bainitic transformation, $\Delta G^{\gamma \alpha}$, provides an estimation of the kinetics of the transformation; at a given temperature, higher absolute values mean a faster transformation, and again, the results are almost identical.
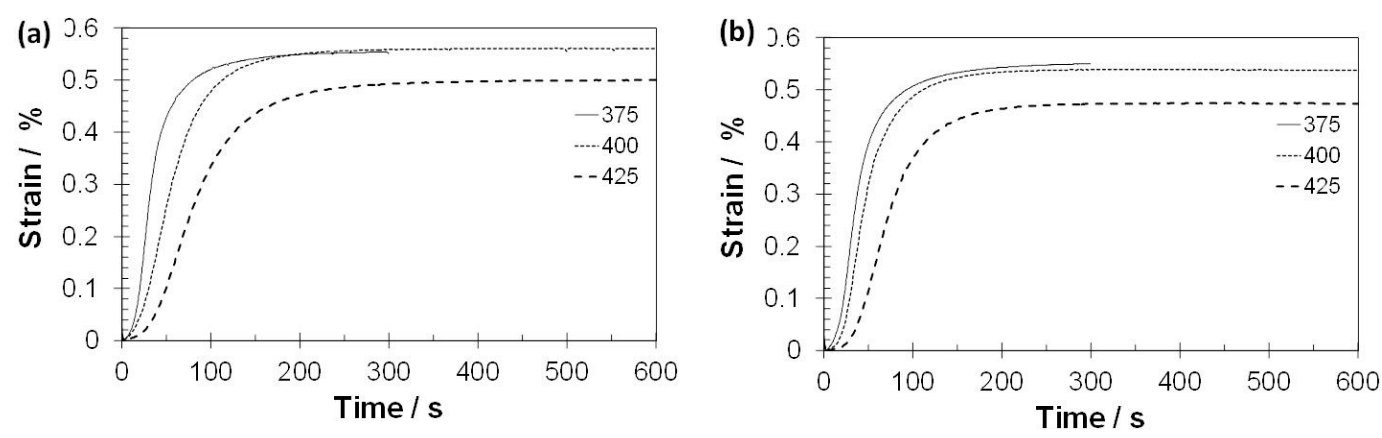

Figure 7. Strain-time curves during bainitic isothermal transformation at different temperatures.
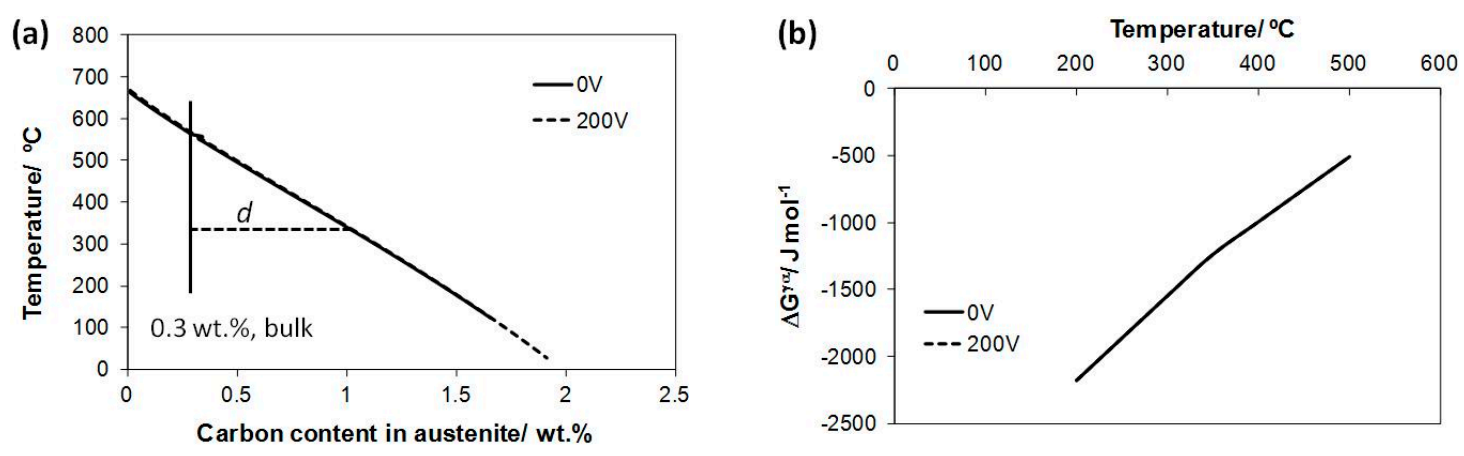

Figure 8. Theoretical calculations of the (a) $T_{0}$ line and (b) free energy change for bainitic transformation $\Delta G^{\gamma \alpha}$.

Table 4. Time, in seconds, to reach $90 \%$ of the maximum strain during isothermal holding at the indicated temperature; specimens were austenitized at $1150{ }^{\circ} \mathrm{C}$ for $3 \mathrm{~min}$ and cooled down to the isothermal temperature at $20^{\circ} \mathrm{C} / \mathrm{s}$.

\begin{tabular}{cccc}
\hline Alloy & $\mathbf{3 7 5}{ }^{\circ} \mathrm{C}$ & $\mathbf{4 0 0}{ }^{\circ} \mathrm{C}$ & $\mathbf{4 2 5}{ }^{\circ} \mathrm{C}$ \\
\hline $0 \mathrm{~V}$ & 79 & 118 & 168 \\
$200 \mathrm{~V}$ & 89 & 99 & 135 \\
\hline
\end{tabular}

After bainitic transformation, during cooling to room temperature, there is a chance for the retained austenite to transform to martensite, at a higher fraction as the transformation temperature increases. This has been observed in the corresponding dilatometry, and the amount of martensite has been estimated from the curves, as shown in Table 5 [33,34]. However, there is a softening of the microstructure with the increasing transformation temperature, lower HV values, which are consistent with smaller fractions of bainite, as shown in Figure 8, and coarser bainitic ferrite plates [27,35]. This argument is also valid to explain the increase in HV detected for the $200 \mathrm{~V}$ alloy as compared to the $0 \mathrm{~V}$ alloy, as the expected fraction of the different phases present in the microstructure at a given temperature is the same for both alloys, as shown in Figure 8 and Table 5. Figure 9 shows examples of the microstructures after partial transformation at $425{ }^{\circ} \mathrm{C}$ for both alloys. The origin of these 
interrupted isothermal heat treatments is out of the scope of this investigation, but it illustrates the differences in the scale of the attained microstructures at a given transformation temperature. These results are in line with those presented for the normalized samples.
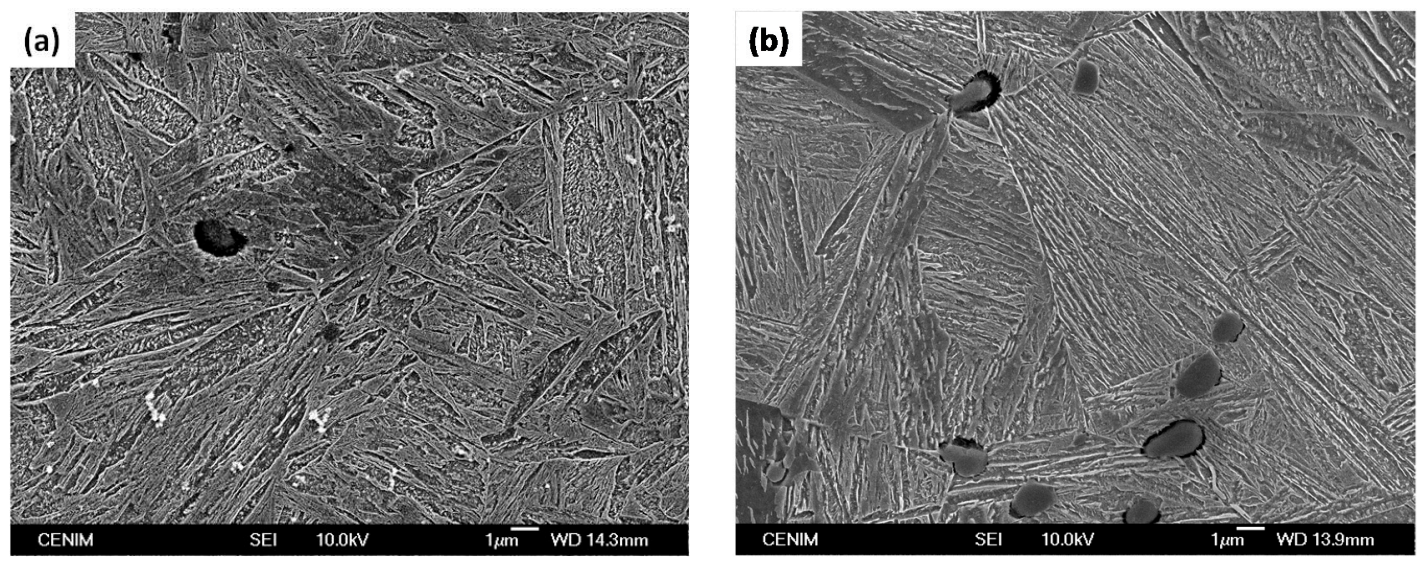

Figure 9. Microstructure after partial transformation at $425^{\circ} \mathrm{C}$ for (a) $0 \mathrm{~V}$ alloy and (b) $200 \mathrm{~V}$ alloy.

Table 5. Martensite fraction (\%) and HV after isothermal transformation at different temperatures.

\begin{tabular}{ccccc}
\hline Isothermal & \multicolumn{2}{c}{$\mathbf{0 ~ V}$} & \multicolumn{2}{c}{$\mathbf{2 0 0 ~ V}$} \\
\cline { 2 - 5 } Temperature $\left({ }^{\circ} \mathbf{C}\right)$ & Martensite (\%) & HV & Martensite (\%) & HV \\
\hline $375^{\circ} \mathrm{C}$ & 0 & 439 & 0 & 451 \\
$400^{\circ} \mathrm{C}$ & 5 & 379 & 5 & 438 \\
$425^{\circ} \mathrm{C}$ & 10 & 380 & 15 & 400 \\
\hline
\end{tabular}

It should be noted that bainite nucleates on the parent austenite grains; therefore, and without a doubt, the austenite grain size has an effect on the overall kinetics of the isothermal transformation of bainite [36]. This effect is not accounted for in the theoretical calculations of the type shown in Figure 8 which only consider the chemical composition of the steel. In general, it is found that a refinement of the austenite grain structure leads to an acceleration of the rate of transformation, and the overall reaction is limited by a slow growth rate [36-39]. On the other hand, there are a few cases where the reaction is controlled by a rapid growth from a limited number of nucleation sites, and a reduction in the austenite grain size reduces the total volume transformed per nucleus and hence retards the overall reaction rate $[37,40]$. For the particular system at hand and with the data in Table 4 and Figure $8 b$, with almost the same experimental and theoretical transformation kinetics, and the increase in average grain size from 12 to $22 \mu \mathrm{m}$, we could rationalize both scenarios. Assuming a deceleration of the bainitic transformation as the PAGS is increased, the effect of $\mathrm{V}$ in solid solution leads to an acceleration of the transformation. On the other hand, if we accept that the increase of PAGS leads to an acceleration of bainite formation, $\mathrm{V}$ in solid solution must be decelerating the whole transformation. In either case it is clear that $\mathrm{V}$ in solid solution must be playing an important role in the transformation kinetics. In contrast to this argument, it could be pointed that the presence of $\mathrm{V}$ precipitates can enhance the transformation by promoting the heterogeneous nucleation of bainite [41,42], acicular ferrite, thus counteracting the effect of the increment in PAGS. This argument does not hold up, as at the end of the bainitic transformation the $\mathrm{V}$ distribution is expected to be the same as that described for the normalized samples, shown in Table 3. At the isothermal temperature range used, $375-425^{\circ} \mathrm{C}$, any evolution is very unlikely, particularly given the cooling rate in use, $20^{\circ} \mathrm{C} / \mathrm{s}$. Therefore, it is expected that all the $\mathrm{V}$, before and after the bainitic transformation, is in solid solution. 


\section{Conclusions}

This work has investigated the influence of $\mathrm{V}$ content on the hardenability and the bainitic transformation of a medium carbon forging steel. It has been shown that for the austenitization temperatures of 1000 and $1150{ }^{\circ} \mathrm{C}$, the vast majority of the $\mathrm{V}$ was in solid solution. In terms of hardenability, $\mathrm{V}$ in solution has the expected delaying effect on all the phase transformations taking place during continuous cooling. However, as for the isothermal transformation of bainite, the influence is not clear. In the present case the existence of two possible phenomena that can affect the kinetics of bainite, i.e., different grain size of austenite and $\mathrm{V}$ in solid solution, is discussed and leads us to conclude that it is possible that the presence of $\mathrm{V}$ in solution is, in fact, affecting the kinetics of the bainitic transformation.

An unexpected outcome of the study is the increase in the average prior austenite grain size with the $\mathrm{V}$ content, and it is speculated that the presence of $\mathrm{V}$ might be affecting the $\operatorname{Ti}(\mathrm{C}, \mathrm{N})$ precipitation. Ongoing research is trying to clarify some of the questions raised in this work.

Acknowledgments: The authors would like acknowledge the financial support of Vanitec through a research contract between the participants in this work.

Author Contributions: David Milbourn and Thomas Sourmail conceived and designed the research. Thomas Sourmail, Carlos Garcia-Mateo and Francisca G. Caballero designed the experiments; Lucia Morales-Rivas, Thomas Sourmail and Carlos Garcia-Mateo performed the experiments and analyzed the data. Carlos Garcia-Mateo and Thomas Sourmail wrote the manuscript. Thomas Sourmail, Carlos Garcia-Mateo, Lucia Morales-Rivas, David Milbourn and Francisca G. Caballero revised the manuscript.

Conflicts of Interest: The authors declare no conflict of interest.

\section{References}

1. Gladman, T. The Physical Metallurgy of Microalloyed Steels; Institute of Materials: London, UK, 1997.

2. Bhadeshia, H.K.D.H. Bainite in Steels: Theory and Practice, 3rd ed.; Maney Publishing: Leeds, UK, $2015 ;$ p. 616.

3. Bhadeshia, H.K.D.H.; Honeycombe, R.W.K. Steels: Microstructure and Properties; Butterworths-Heinemann (Elsevier): Oxford, UK, 2006.

4. Takahashi, M.; Bhadeshia, H.K.D.H. Model for transition from upper to lower bainite. Mater. Sci. Technol. 1990, 6, 592-603. [CrossRef]

5. Takahashi, M.; Bhadeshia, H.K.D.H. A model for the microstructure of some advanced bainitic steels. Mater. Trans. JIM 1991, 32, 689-696. [CrossRef]

6. Gomez, G.; Perez, T.; Bhadeshia, H.K.D.H. Air cooled bainitic steels for strong, seamless pipes part 2-Properties and microstructure of rolled material. Mater. Sci. Technol. 2009, 25, 1508-1512. [CrossRef]

7. Gomez, G.; Perez, T.; Bhadeshia, H.K.D.H. Air cooled bainitic steels for strong, seamless pipes part 1-Alloy design, kinetics and microstructure. Mater. Sci. Technol. 2009, 25, 1501-1507. [CrossRef]

8. Sugimoto, K.-I.; Yoshikawa, N. Advanced high-strength trip-aided steels for ultra high pressure DI-diesel engine common rail. In 3rd International SCT Conference Steels for Cars and Trucks SCT2011; Wieland, H.J., TEMA Technologie Marketing AG, Eds.; Stahleisen: Salzburg, Austria, 2011; pp. 460-467.

9. Sourmail, T.; Michaud, H.; d'Eramo, E.; Baudry, G. Microalloyed bainitic steels for high performance forged mechanical components. In 2nd International Conference Super-High Strength Steels; AIM, Ed.; Associazione Italiana di Metallurgia: Verona, Italy, 2010.

10. Hasler, S.; Roelofs, H.; Lembke, M.; Caballero, F.G. New air cooled steels with outstanding impact toughness. In 3rd International SCT Conference Steels for Cars and Trucks SCT2011; Wieland, H.J., TEMA Technologie Marketing AG, Eds.; Stahleisen: Salzburg, Austria, 2011; pp. 330-337.

11. Woodhead, J.H. The physical metallurgy of vanadium steels. In Proc. Semin. Vanadium'79; Vanitec: Chicago, IL, USA, 1979; pp. 3-10.

12. Grange, R.A. Estimating the hardenability of carbon steels. Metall. Trans. 1973, 4, 2231-2244. [CrossRef]

13. Adrian, H. A mechanism for effect of vanadium on hardenability of medium carbon manganese steel. Mater. Sci. Technol. 1999, 15, 366-378. [CrossRef]

14. Gol'dshtein, M.I.; Guterman, S.G. Effect of small amounts of vanadium on the hardenability of structural carbon steel. Met. Sci. Heat Treat. 1965, 6, 440-442. [CrossRef] 
15. Garbarz, B.; Pickering, F.B. Effect of austenite grain boundary mobility on hardenability of steels containing vanadium. Mater. Sci. Technol. 1988, 4, 967-975. [CrossRef]

16. Garbarz, B.; Pickering, F.B. Effect of vanadium and austenitising temperature on hardenability of (0.2-0.3)c-1.6 mn steels with and without additions of titanium, aluminium, and molybdenum. Mater. Sci. Technol. 1988, 4, 117-126. [CrossRef]

17. Tsunekage, N.; Kobayashi, K.; Tsubakino, H. Influence of sulphur and vanadium additions on toughness of bainitic steels. Mater. Sci. Technol. 2001, 17, 847-855. [CrossRef]

18. Kim, K.S.; Du, L.X.; Gao, C.R. Influence of vanadium content on bainitic transformation of a low-carbon boron steel during continuous cooling. Acta Metall. Sin. 2015, 28, 692-698. [CrossRef]

19. He, K.; Edmonds, D.V. Formation of acicular ferrite and influence of vanadium alloying. Mater. Sci. Technol. 2002, 18, 289-296. [CrossRef]

20. Siwecki, T.; Eliasson, J.; Lagneborg, R.; Hutchinson, B. Vanadium microalloyed bainitic hot strip steels. ISIJ Int. 2010, 50, 760-767. [CrossRef]

21. Li, Y.; Milbourn, D. Vanadium in bainitic steels: A review of recent developments. In Advanced Steels: The Recent Scenario in Steel Science and Technology; Weng, Y., Dong, H., Gan, Y., Eds.; Springer Berlin Heidelberg: Berlin, Germany, 2011; pp. 303-308.

22. Hutchinson, B.; Siwecki, T.; Komenda, J.; Hagström, J.; Lagneborg, R.; Hedin, J.E.; Gladh, M. New vanadium-microalloyed bainitic $700 \mathrm{MPa}$ strip steel product. Ironmak. Steelmak. 2014, 41, 1-6. [CrossRef]

23. San Martín, D.; Palizdar, Y.; Cochrane, R.C.; Brydson, R.; Scott, A.J. Application of nomarski differential interference contrast microscopy to highlight the prior austenite grain boundaries revealed by thermal etching. Mater. Charact. 2010, 61, 584-588. [CrossRef]

24. ASTM E975-13. Standard Practice for X-ray Determination of Retained Austenite in Steel with Near Random Crystallographic Orientation; ASTM International: West Conshohocken, PA, USA, 2013.

25. Dickson, M.J. Significance of texture parameters in phase analysis by X-ray diffraction. J. Appl. Crystallogr. 1969, 2, 176-180. [CrossRef]

26. Mtdata, version 4.73. National Physical Laboratory: Teddington, UK, 2003. National Physical Laboratory: Teddington, UK, 2003. National Physical Laboratory: Teddington, UK, 2003.

27. Cornide, J.; Garcia-Mateo, C.; Capdevila, C.; Caballero, F.G. An assessment of the contributing factors to the nanoscale structural refinement of advanced bainitic steels. J. Alloy. Compd. 2013, 577, S43-S47. [CrossRef]

28. Staśko, R.; Adrian, H.; Adrian, A. Effect of nitrogen and vanadium on austenite grain growth kinetics of a low alloy steel. Mater. Charact. 2006, 56, 340-347. [CrossRef]

29. Glodowski, R.J. A review of vanadium microalloying in hot rolled steel sheet products. In International Seminar 2005 on Application Technologies of Vanadium in Flat-Rolled Steels; Vanitec: Suzhou, China, 2005; pp. 43-51.

30. Garcia-Mateo, C.; Lopez, B.; Rodriguez-Ibabe, J. Static recrystallization kinetics in warm worked vanadium microalloyed steels. Mater. Sci. Eng. A 2001, 303, 216-225. [CrossRef]

31. Lagneborg, R.; Siwecki, T.; Zajac, S.; Hutchinson, B. Role of vanadium in microalloyed steels. Scand. J. Metall. 1999, 28, 186-241.

32. Garcia-Mateo, C.; Caballero, F.G. Advanced high strength bainitic steels. In Comprehensive Materials Processing; Hashmi, S., Batalha, G.F., Tyne, C.J.V., Yilbas, B., Eds.; Elsevier Ltd.: Oxford, UK, 2014; Volume 1, pp. 165-190.

33. Mittemeijer, E.J. Fundamentals of Materials Science: The Microstructure-Property Relationship Using Metals as Model Systems; Springer Berlin Heidelberg: Berlin, Germany, 2010.

34. Takahashi, M.; Bhadeshia, H.K.D.H. The interpretation of dilatometric data for transformations in steels. J. Mater. Sci. Lett. 1989, 8, 477-478. [CrossRef]

35. Garcia-Mateo, C.; Caballero, F.; Bhadeshia, H. Development of hard bainite. ISIJ Int. 2003, 43, 1238-1243. [CrossRef]

36. Matsuzaki, A.; Bhadeshia, H.K.D.H. Effect of austenite grain size and bainite morphology on overall kinetics of bainite transformation in steels. Mater. Sci. Technol. 1999, 15, 518-522. [CrossRef]

37. Garcia-Mateo, C.; Caballero, F.; Bhadeshia, H. Acceleration of low-temperature bainite. ISIJ Int. 2003, 43, 1821-1825. [CrossRef]

38. Barford, J.; Owen, W.S. The effect of austenite grain size and temperature on the rate of bainite transformation. Met. Sci. Heat Treat. Met. 1961, 4, 359-360. 
39. Umemoto, M.; Horiuchi, K.; Tamura, I. Transformation kinetics of bainite during isothermal holding and continuous cooling. Trans. Iron Steel Inst. Jpn. 1982, 22, 854-861. [CrossRef]

40. Hu, F.; Hodgson, P.D.; Wu, K.M. Acceleration of the super bainite transformation through a coarse austenite grain size. Mater. Lett. 2014, 122, 240-243. [CrossRef]

41. Garcia-Mateo, C.; Capdevila, C.; Caballero, F.G.; de Andres, C.G. Influence of V precipitates on acicular ferrite transformation part 1: The role of nitrogen. ISIJ Int. 2008, 48, 1270-1275. [CrossRef]

42. Garcia-Mateo, C.; Cornide, J.; Capidevila, C.; Caballero, F.G.; de Andres, C.G. Influence of V precipitates on acicular ferrite transformation part 2: Transformation kinetics. ISIJ Int. 2008, 48, 1276-1279. [CrossRef]

(C) 2016 by the authors; licensee MDPI, Basel, Switzerland. This article is an open access article distributed under the terms and conditions of the Creative Commons Attribution (CC-BY) license (http://creativecommons.org/licenses/by/4.0/). 